TITLE:

\title{
$<$ Note> Possible Intergroup Killing in Chimpanzees in the Kalinzu Forest, Uganda
}

\section{$\operatorname{AUTHOR}(\mathrm{S})$ :}

Hashimoto, Chie; Furuichi, Takeshi

\section{CITATION:}

Hashimoto, Chie ...[et al]. < Note> Possible Intergroup Killing in

Chimpanzees in the Kalinzu Forest, Uganda. Pan Africa News 2005,

$12(1): 3-5$

ISSUE DATE:

2005-06

URL:

http://hdl.handle.net/2433/143451

RIGHT:

Copyright (C) Pan Africa News. 
<NOTE>

Possible Intergroup Killing in Chimpanzees in the Kalinzu Forest, Uganda

Chie Hashimoto ${ }^{1}$ and Takeshi Furuichi ${ }^{2}$

1. Primate Research Institute, Kyoto University

2. Faculty of Foreign Studies, Meiji-Gakuin University

\section{INTRODUCTION}

Several studies have reported intergroup killing of adult male chimpanzees (Pan troglodytes schweinfurthii $)^{1,2,3}$. Although there has been criticism that the intergroup killing occurred as a result of artificial provisioning or playback experiments, a recent study has confirmed that it occurred in a wild group in the Kibale National Park, Ngogo group, a group that had not been under any artificial influences ${ }^{3}$. We have also observed a wild group of chimpanzees, in the Kalinzu Forest Reserve, Uganda, a group with no experience of artificial provisioning or experiments. Here, we report an indirect observation that suggests the occurrence of the intergroup killing of an adult male.

\section{METHODS}

We have been studying wild chimpanzees in the Kalinzu Forest Reserve since $1992^{4}$. We started to habituate one group, $M$ group, in June 1997. Most of the adult male members were well habituated by $2001^{4}$. The observations for this report were conducted from August 2003 to October 2003. During this period, we followed the M Group and recorded feeding behaviors and 


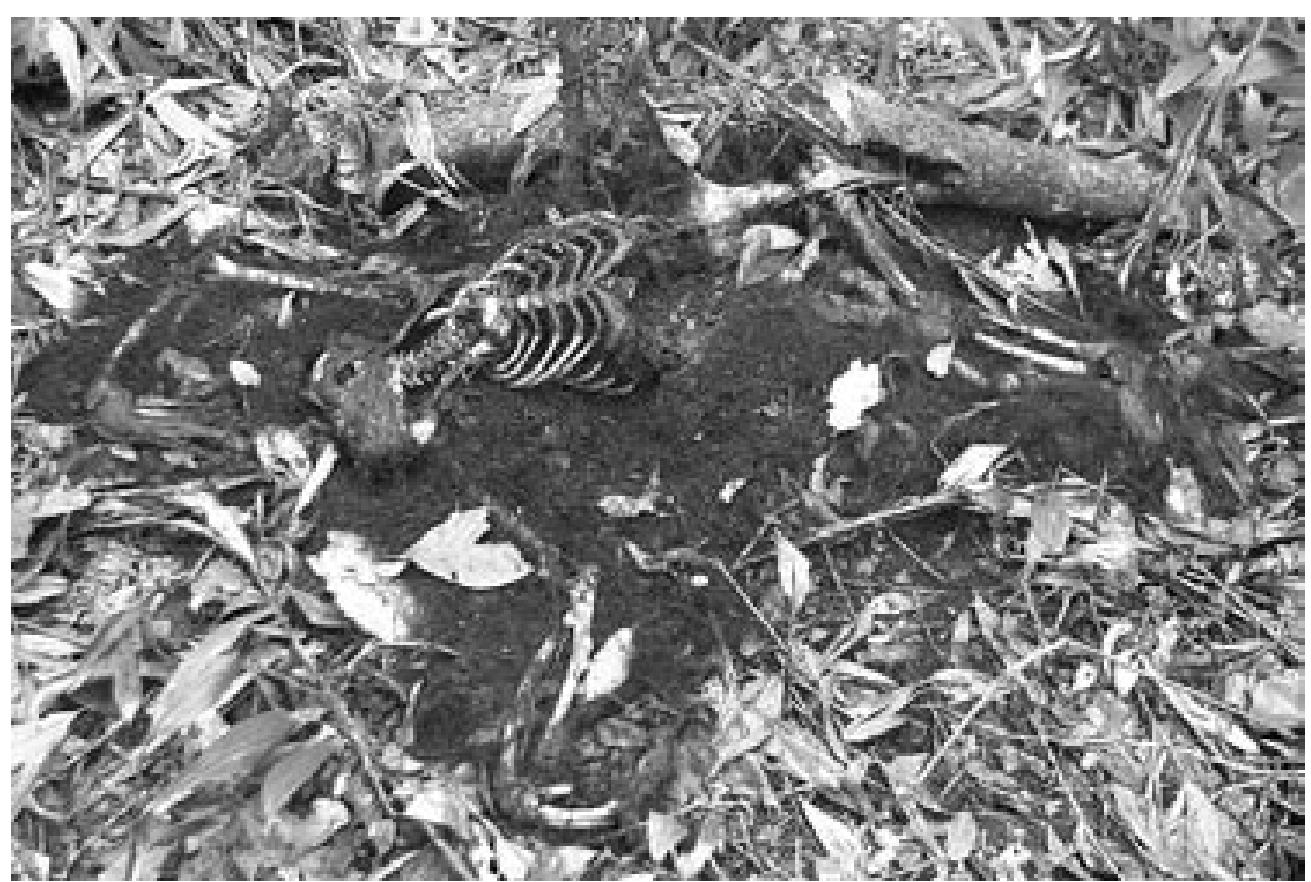

Fig. 1. The carcass of an adult male chimpanzee. The grass was trampled around the carcass.

social interactions using the focal animal and ad lib sampling methods.

\section{RESULTS}

While we stayed in camp, on September 13, 2003, we heard loud vocalizations coming from numerous chimpanzees in the forest. We estimated that the vocalizations had come from a distance of about $500 \mathrm{~m}$. The vocalizations included pant-hoots and screams. This was unusual because it continued for more than ten minutes, without interruption.

Two weeks later, we found the carcass of a male chimpanzee in the area where we had heard the vocalization. Judging from the condition of the carcass, the chimpanzee had died two to three weeks previously (Fig. 1). We also found signs of fighting within $10 \mathrm{~m}$ of the carcass: a wisp of chimpanzee hair on the ground, broken branches, and trampled grass.

The carcass was identified as a prime adult male chimpanzee from a photo-identification of the teeth (Mouri and Nakai personal communication). Since that time, a prime adult male, named Nui, who was estimated to be 30-35 years old, has never been observed. As all the other adult male members have been confirmed to be alive, we postulate that the carcass was that of Nui.

In 2003, the $M$ group home range was narrower than in the previous year, and we frequently observed a neighboring group in the area from which the $\mathrm{M}$ group had retreated. The carcass was found on the boundary of the $\mathrm{M}$ group home range in this area (Fig. 2). We also observed three agonistic encounters with a neighboring group near the boundary. One case occurred on the same day that we observed the carcass, $100 \mathrm{~m}$ away from it. We also observed patrolling by the $\mathrm{M}$ group males more often than we had in previous study periods. Based on these circumstances, we postulated that Nui had been killed in an agonistic interaction between the groups.

\section{DISCUSSION}

Intergroup killing in chimpanzees has been reported at several study sites ${ }^{1,2,3}$. Although we did not make a direct observation, the possible killing occurred when a neighboring group invaded the home range of $M$ Group. Since 2001, a part of the home range of the neighboring group has been logged. The neighboring group appears to have shifted its home range eastward, following deforestation in their home range. Previous studies have suggested that intergroup killing increases survivorship for the attackers by increasing territory size ${ }^{3}$. Our study also suggests that a territory shift or expansion caused an intergroup killing in chimpanzees.

\section{ACKNOWLEDGEMETNS}

We thank the Uganda National Council for Science and Technology, the Uganda National Forestry Authority, the Uganda Wildlife Authority. We also thank Dr. Mouri for the identification of the carcass. This study was supported by a grant from the Monbusho International Scientific Research Program (\#12375003 to T. Nishida). 


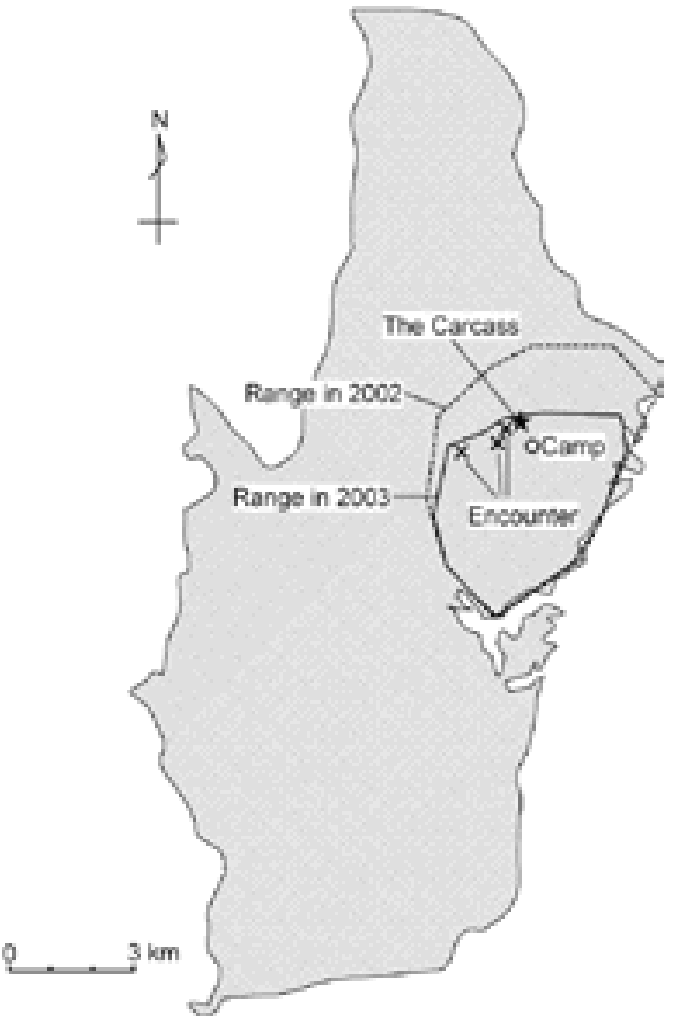

Fig. 2. The $M$ group home range in the current study period (2003), and in the previous year (2002). The locations of the camp, carcass, and the occurrence of agonistic encounters are also indicated.

\section{REFERENCES}

1. Nishida T, Hiraiwa-Hasegawa M, Hasegawa T and Takahata Y. 1985. Group extinction and female transfer in wild chimpanzees in the Mahale National Park Tanzania. Z. Tierpsychol. 67:284-301.

2. Goodall J. 1986. The Chimpanzees of Gombe, Harvard University Press, Cambridge, MA.

3. Watts DP. 2004. Intracommunity coalitionary killing of an adult male chimpanzee at Ngogo, Kibale National Park, Uganda. Inter. J. Primatol. 25: 507-521.

4. Hashimoto C, Furuichi T, Tashiro Y. 2001. What factors affect the size of chimpanzee parties in the Kalinzu Forest, Uganda? Examination of fruit abundance and number of estrous females. Int. $J$. Primatol. 22: 947-959. 